\title{
BMJ Open Effectiveness of a pharmacist-led educational intervention to reduce the use of high-risk abbreviations in an acute care setting in Saudi Arabia: a quasi-experimental study
}

\author{
Abdul Haseeb, ${ }^{1}$ Win Winit-Watjana, ${ }^{2}$ Abdul-Rahman R Bakhsh, ${ }^{3}$ \\ Mahmoud E Elrggal, ${ }^{1,4}$ Muhammad Abdul Hadi, ${ }^{1}$ Alaa A Mously, ${ }^{5}$ \\ Asmaa Z Gadibalban, ${ }^{1}$ Bashayir F Al-Ibraheem, ${ }^{6}$ Rasha A Almubark, ${ }^{7}$ \\ Rawan A Ekram, ${ }^{1}$ Tahir Mehmood Khan ${ }^{8}$
}

To cite: Haseeb A, WinitWatjana W, Bakhsh A-RR, et al. Effectiveness of a pharmacist-led educational intervention to reduce the use of high-risk abbreviations in an acute care setting in Saudi Arabia: a quasi-experimental study. BMJ Open 2016;6: e011401. doi:10.1136/ bmjopen-2016-011401

- Prepublication history for this paper is available online. To view these files please visit the journal online (http://dx.doi.org/10.1136/ bmjopen-2016-011401).

Received 4 February 2016 Revised 17 May 2016 Accepted 24 May 2016

CrossMark

For numbered affiliations see end of article.

Correspondence to Dr Tahir Mehmood Khan; tahir.mehmood@monash.edu

\section{ABSTRACT}

Objectives: To evaluate the effectiveness of a pharmacist-led educational intervention to reduce the use of high-risk abbreviations (HRAs) by healthcare professionals.

Design: Quasi-experimental study consisting of a single group before-and-after study design.

Setting: A public emergency hospital in Mecca, Saudi Arabia.

Participants: 660 (preintervention) and then 498 (postintervention) handwritten physician orders, medication administration records (MRAs) and pharmacy dispensing sheets of 482 and 388 patients, respectively, from emergency wards, inpatient settings and the pharmacy department were reviewed.

Intervention: The intervention consisted of a series of interactive lectures delivered by an experienced clinical pharmacist to all hospital staff members and dissemination of educational tools (flash cards, printed list of HRAs, awareness posters) designed in line with the recommendations of the Institute for Safe Medical Practices and the US Food and Drug Administration. The duration of intervention was from April to May 2011.

Main outcome: Reduction in the incidence of HRAs use from the preintervention to postintervention study period.

Findings: The five most common abbreviations recorded prior to the interventions were 'IJ for injection' (28.6\%), 'SC for subcutaneous' (17.4\%), drug name and dose running together $(9.7 \%)$, 'OD for once daily' $(5.8 \%)$ and ' $\mathrm{D} / \mathrm{C}$ for discharge' $(4.3 \%)$. The incidence of the use of HRAs was highest in discharge prescriptions and dispensing records $(72.7 \%)$ followed by prescriptions from in-patient wards (47.3\%). After the intervention, the overall incidence of HRA was significantly reduced by $52 \%$ (ie, $53.6 \%$ vs $25.5 \%$; $\mathrm{p}=0.001$ ). In addition, there was a statistically significant reduction in the incidence of HRAs across all three settings: the pharmacy department $(72.7 \%$ vs

\section{Strengths and limitations of this study}

- This is the first adequately powered study to evaluate the effectiveness of a pharmacist-led educational intervention to reduce the incidence of high-risk abbreviations (HRAs) in an acute care setting.

- A quasi-experimental design is best suited to evaluate the effectiveness of an intervention when conducting a randomised controlled trial is not logistically feasible.

- Findings from the present study can assist policymakers to design policies to encourage safe prescribing practices, thus reducing medication errors.

- Quasi-experimental studies using a single group before-and-after study design have poor internal validity.

- We could not study the negative consequences (eg, adverse drug reactions) of using HRAs and the impact of reducing the incidence of using HRAs on patient safety.

$39.3 \%$ ), inpatient settings ( $47.3 \%$ vs $23.3 \%$ ) and emergency wards ( $40.9 \%$ vs $10.7 \%$ ).

Conclusions: Pharmacist-led educational interventions can significantly reduce the use of HRAs by healthcare providers. Future research should investigate the long-term effectiveness of such educational interventions through a randomised controlled trial.

\section{INTRODUCTION}

Medication errors are one of the major causes of morbidity and mortality globally and the most prevalent error in medical care. $^{1}$ These errors can occur while 
prescribing, dispensing and administering medicines, and most of them are preventable before they harm patients. ${ }^{1}{ }^{2}$ In hospitals, prescription and administration errors are major threats to patient safety, with an estimated incidence of $18.9-58.4 \% .^{1-5}$ There are many reasons why medication errors occur, but in most cases the errors can be linked to poor communication or transcribing of the physician's message. A contributing factor in poor communication is the use of shorthand or ambiguous abbreviations when writing prescriptions. ${ }^{5}$ Although the use of abbreviations is time saving, it does not promote patient safety. ${ }^{6}{ }^{7}$ In the USA, it has been estimated that $\sim 5 \%$ of medication errors reported in medical care are associated with the use of unsafe abbreviations leading to patient harm. ${ }^{8}$

Using shorthand or abbreviations in prescriptions tends to become habitual practice if not discouraged. On-the-job training or educational activities have been shown to be a significant help in the eradication of this habit, with several studies having confirmed that educational interventions are an effective tool for the improvement of prescribing skills and, consequently, patient safety. ${ }^{9-12}$ The Institute for Safe Medical Practices (ISMP), together with the US Food and Drug Administration (FDA), launched a nationwide educational campaign in 2006 to prevent the use of unsafe and error-prone abbreviations in healthcare facilities and developed a list of abbreviations, symbols and dose designations that should be avoided while communicating all sorts of medical information. ${ }^{13}{ }^{14}$ Subsequently, many countries have followed suit. For instance, the New South Wales Therapeutics Advisory Group (NSWTAG) developed quality indicators according to the ISMP and FDA recommendations to discontinue the use of abbreviations in Australian hospitals. ${ }^{15}$

Another concept that has been the focus of attention in this regard is the increased emphasis on promoting a safety culture during the teaching and training of medical students and residents. ${ }^{7-9}$ Pharmacist-led educational interventions have been shown to improve safe prescribing practices as well. ${ }^{12}$

Like any other country, medication errors are of great concern in Saudi Arabia. Although the overall incidence of medication errors in the Kingdom is not available, studies have reported a prescribing error incidence of 8-56 per 100 medication orders in hospitalised patients. ${ }^{16} 17$ In Saudi Arabia, the healthcare workforce largely consists of expatriates educated and trained in different countries including, but not limited to, the UK, the USA, India, Pakistan, Egypt, Malaysia and the Philippines. In addition, Saudi Arabia attracts more than 10 million pilgrims across the globe to visit holy mosques each year who receive free medical treatment, if required. Therefore, given the high number of patients and diversity of healthcare workforce (in terms of culture, language, clinical education and training), healthcare providers may use high-risk abbreviations (HRA) that could in turn lead to prescribing, transcribing and administration errors, especially in acute care facilities dealing with pilgrims. To the best of our knowledge, no study has evaluated the extent of use of HRAs in an acute care setting and impact of a pharmacist-led educational intervention to reduce the use of HRAs. Therefore, the aim of this study was to evaluate the effectiveness of a pharmacist-led educational intervention to reduce the use of HRA by healthcare professionals (ie, doctors, nurses, pharmacists and relevant assistants) in an acute care setting.

\section{Method}

A quasi-experimental study using a single group before-and-after intervention design ${ }^{18}$ was conducted from 1 February 2011 to 1 July 2011. Although randomised controlled trials (RCTs) are best suited to evaluate the effectiveness of an intervention, ${ }^{19}$ we were unable to design an RCT due to the unavailability of a suitable control group. The limitations of using a quasi-experimental design are further discussed in the limitations section. The primary outcome was reduction in the incidence of HRAs, as a proportion of all prescriptions, from the preintervention to postintervention period.

\section{Settings}

The study was conducted at an acute care facility specially designated for pilgrims visiting Majsid-Al-Haram (The Grand Mosque), Mecca, Saudi Arabia. The hospital on average provides emergency care to more than 5000 pilgrims a year. In addition to the outpatient department and the pharmacy department, the hospital has a 10-bed Coronary Care Unit (CCU) and 10-bed Intensive Care Unit (ICU).

\section{Identification of prescriptions with HRA}

During the study period, electronic prescribing was limited to inpatient physician orders only. All handwritten physician orders, medication administration records (MRAs) and pharmacy dispensing sheets from the inpatient (ICU and CCU), outpatient (male and female emergency wards) and pharmacy departments were reviewed for HRAs by six senior pharmacy students, who had received formal training in clinical research and data collection, under the direct supervision of the first author (AH). For the purpose of this study, HRAs referred to 'medical abbreviations, dose designations, drug names, or symbols considered unsafe and likely to result in misinterpretation.' These were identified on the basis of the ISMP's list of error-prone abbreviations by a team of experienced pharmacists based on hospital usage. ${ }^{13}$ At first, 62 abbreviations were selected, but these were later narrowed down to 32 items, based on the frequency of use and severity of the consequences. Details of abbreviations are listed in table 1.

\section{Sample size}

The sample size for this study was estimated on the basis of the method previously adopted by Abushaiqa et al. ${ }^{12}$ 
Table 1 List of high-risk abbreviations used in this study

\begin{tabular}{|c|c|c|c|c|}
\hline & High-risk item & Intended meaning & Possible misinterpretation & Preferred correction \\
\hline & \multicolumn{4}{|l|}{ Abbreviations } \\
\hline 1. & $\mu \mathrm{g}$ & Microgram & $\mathrm{mg}$ & Write 'mcg' \\
\hline 2. & BT & Bedtime & BID (twice daily) & Use 'bedtime' \\
\hline 3. & $\mathrm{cc}$ & Cubic centimetres & u (units) & Use 'mL' \\
\hline 4. & $\mathrm{D} / \mathrm{C}$ & $\begin{array}{l}\text { Discharge or } \\
\text { discontinue }\end{array}$ & Either one & $\begin{array}{l}\text { Use 'discharge' or } \\
\text { 'discontinue' }\end{array}$ \\
\hline 5. & IJ & Injection & IV or intrajugular & Injection \\
\hline 6. & HS & $\begin{array}{l}\text { Bedtime or } \\
\text { half-strength }\end{array}$ & Either one & $\begin{array}{l}\text { Use 'bedtime' or } \\
\text { 'half-strength' }\end{array}$ \\
\hline 7. & IU & International units & IV or 10 (ten) & Use 'units' \\
\hline 8. & o.d. or OD & Once daily & $\begin{array}{l}\text { Right eye, leading to oral liquid } \\
\text { instilled in to the eye }\end{array}$ & Use 'daily' \\
\hline 9. & q.d. or QD & Every day & q.i.d.(four times daily) & Use 'daily' \\
\hline 10. & q.o.d. or QOD & Every other day & q.d. or q.i.d. & Use 'every other day' \\
\hline 11. & $S C, S Q$, sub q & Subcutaneous & $\begin{array}{l}\text { SC as SL (sublingual), SQ as '5 } \\
\text { every', q as 'every' }\end{array}$ & $\begin{array}{l}\text { Use 'subcut' or } \\
\text { 'subcutaneously' }\end{array}$ \\
\hline 12. & ss & $\begin{array}{l}\text { Sliding scale (insulin) } \\
\text { or } 1 / 2\end{array}$ & ‘55’ & $\begin{array}{l}\text { Spell out 'sliding scale' or } \\
\text { use 'one-half' or ' } 1 / 2 \text { ' }\end{array}$ \\
\hline 13. & \multicolumn{4}{|l|}{$\mathrm{U}$ or $\mathrm{u}$} \\
\hline 14. & $\begin{array}{l}\text { Trailing zero after a decimal } \\
\text { point }(\mathrm{eg}, 1.0 \mathrm{mg})\end{array}$ & $1 \mathrm{mg}$ & $\begin{array}{l}10 \mathrm{mg} \text { if the decimal point is not } \\
\text { seen }\end{array}$ & Express in whole numbers \\
\hline 15. & $\begin{array}{l}\text { No leading zero before a } \\
\text { decimal point (eg, } 0.5 \mathrm{mg} \text { ) }\end{array}$ & $0.5 \mathrm{mg}$ & $\begin{array}{l}5 \mathrm{mg} \text { if the decimal point is not } \\
\text { seen }\end{array}$ & $\begin{array}{l}\text { Use zero before the } \\
\text { decimal point }\end{array}$ \\
\hline 16. & $\begin{array}{l}\text { Drug name and dose run } \\
\text { together, especially for "L" } \\
\text { ended drugs (eg, } \\
\text { Tegretol300 mg) }\end{array}$ & Tegretol 300 mg & Tegretol $1300 \mathrm{mg}$ & $\begin{array}{l}\text { Place enough space } \\
\text { between the drug, dose, } \\
\text { and unit }\end{array}$ \\
\hline 17. & $\begin{array}{l}\text { Numerical dose and unit of } \\
\text { measure run together (eg, } \\
10 \mathrm{mg}, 100 \mathrm{~mL})\end{array}$ & $10 \mathrm{mg}, 100 \mathrm{~mL}$ & $\begin{array}{l}\text { The 'm' might be mistaken as a } \\
\text { zero or two zeros }\end{array}$ & $\begin{array}{l}\text { Place enough space } \\
\text { between the dose and unit }\end{array}$ \\
\hline 18. & $\begin{array}{l}\text { Unit abbreviations with a } \\
\text { period (eg, mg. or } \mathrm{mL} .)\end{array}$ & $\mathrm{mg}, \mathrm{mL}$ & $\begin{array}{l}\text { The 'period' might be mistaken } \\
\text { as ' } 1 \text { ' }\end{array}$ & $\begin{array}{l}\text { Use } \mathrm{mg}, \mathrm{mL} \text {, etc without a } \\
\text { period }\end{array}$ \\
\hline 19. & $\begin{array}{l}\text { Large doses without properly } \\
\text { placed commas (eg, } 100000 \\
\text { units) }\end{array}$ & 100000 units & $\begin{array}{l}\text { The ' } 100000 \text { ' might be mistaken } \\
\text { as ' } 10000 \text { ' }\end{array}$ & $\begin{array}{l}\text { Use commas for doses } \\
\text { above ' } 1000 \text { ' or write '100 } \\
\text { thousand' instead }\end{array}$ \\
\hline 20. & ASA & $\begin{array}{l}\text { Aspirin or } \\
\text { acetylsalicylic acid }\end{array}$ & $\begin{array}{l}\text { 5-ASA (5-aminosalicylic acid or } \\
\text { mesalazine) or azathioprine }\end{array}$ & Use 'aspirin' \\
\hline 21. & $\mathrm{HCL}$ & $\begin{array}{l}\text { Hydrochloric acid or } \\
\text { hydrochloride }\end{array}$ & $\begin{array}{l}\text { The ' } \mathrm{H} \text { ' is misinterpreted as } \\
\text { ' } \mathrm{K} \text { '-potassium chloride }\end{array}$ & $\begin{array}{l}\text { Use complete drug name } \\
\text { unless expressed as a } \\
\text { drug salt }\end{array}$ \\
\hline 22. & HCT & Hydrocortisone & Hydrochlorothiazide & Use complete drug name \\
\hline 23. & HCTZ & Hydrochlorothiazide & $\begin{array}{l}\text { Hydrocortisone seen as HCT } \\
250 \mathrm{mg}\end{array}$ & Use complete drug name \\
\hline 24. & MgSO4 & Magnesium sulfate & Morphine sulfate & Use complete drug name \\
\hline 25. & MS, MSO4 & Morphine sulfate & Magnesium sulfate & Use complete drug name \\
\hline 26. & MTX & Methotrexate & Mitoxantrone & Use complete drug name \\
\hline 27. & $\begin{array}{l}\text { ZnSO4 } \\
\text { Symbols }\end{array}$ & Zinc sulfate & Morphine sulfate & Use complete drug name \\
\hline 28. & $>$ and $<$ & $\begin{array}{l}\text { Greater than and less } \\
\text { than }\end{array}$ & $\begin{array}{l}\text { Mistaken as opposite of } \\
\text { intended; '<10' mistaken as ' } 40 \text { ' }\end{array}$ & $\begin{array}{l}\text { Use 'greater than' or 'less } \\
\text { than' }\end{array}$ \\
\hline 29. & / (slash) & $\begin{array}{l}\text { Separates two doses } \\
\text { or indicates 'per' }\end{array}$ & $\begin{array}{l}\text { Mistaken as the number ' } 1 \text { ', eg, } \\
25 \text { units/10 units misread as } \\
\text { ' } 25 \text { units and } 110 \text { units' }\end{array}$ & $\begin{array}{l}\text { Use 'per' rather than a } \\
\text { slash mark to separate } \\
\text { doses }\end{array}$ \\
\hline 30. & @ (at sign) & At & Mistaken as '2' & Use 'at' \\
\hline 31. & \& (ampersand) & And & Mistaken as '2' & Use 'and' \\
\hline 32. & $+($ plus sign $)$ & Plus or and & Mistaken as '4' & Use 'and' \\
\hline
\end{tabular}


Taking into account a one-tailed significance level $(\alpha=0.05), \quad \beta=0.2$ and incomplete data $(20 \%)$, the minimum number of prescriptions required for before-and-after-intervention assessment was 130 . However, keeping in mind the chances of sampling errors and limitations of a quasi-experimental single group pretest post-test design, it was decided to review all the prescriptions for at least 1 month before and after the intervention.

\section{Study instruments}

A standardised, structured data collection form was designed on the basis of the criteria presented under the quality indicators developed by the New South Wales Therapeutic Advisory Group and Clinical Excellence Commission. ${ }^{15}$ Section one of the questionnaire gathered information about patient demographics, section two gathered information about the prescribing source and prescriber's name, and finally the third section consisted of the list of HRAs. The content validity of the tool was assessed by the team members and was piloted to test its validity on the first 20 prescriptions.

\section{Pharmacist intervention}

Pretest assessment: This part of the study was designed to get the baseline data about the incidence of HRAs in the study setting. The preassessment phase was initiated in the first week of February 2011 and lasted until the first week of March 2011. Data about the HRAs were collected from all handwritten physician orders, medication administration records and pharmacy dispensing sheets during the study period.

Educational intervention: After collecting the initial data, the educational intervention was undertaken from 2 April to 2 May 2011. The educational intervention was led by an experienced pharmacist with postgraduate qualification in clinical pharmacy $(\mathrm{AH})$ and assisted by senior pharmacy students trained by the research team. The educational intervention was delivered to all healthcare providers and was designed in accordance with the recommendations of ISMP $^{13}$ and the US Food and Drug Administration. ${ }^{14}$ The educational tools included in the intervention were:

- A printed list of abbreviations on brightly coloured paper that was inserted into medical records/patient charts, placed next to all hospital computers and posted in the patient care area $;{ }^{20} 21$

- Pocket-sized flash cards with the HRA list provided for all staff;

- Laminated copies of the list attached to the back of the physician's order divider in medical records;

- Patient safety posters given to the hospital wards explaining the HRAs.

All hospital staff, including physicians, nurses, pharmacists and related staff ( $\sim 250$ people), were requested to attend a series of educational sessions during the intervention phase. The interactive lectures were delivered by $\mathrm{AH}$. The lectures highlighted the basic concepts of medication, prescribing and dispensing errors and negative consequences of using HRAs in emergency settings. In addition, methods of avoiding medication errors and use of HRAs were also discussed. To make sure that all staff were aware of this campaign, each staff member was required to sign a form to confirm that they had received the list and agreed not to use the dangerous abbreviations. At the end of each session, a certificate of attendance was issued to each staff member. Additionally, the research team distributed educational tools (laminated pocket cards with the HRA list, pens and tea mugs with an abbreviation logo) to all participants at the end of the lectures. ${ }^{22}$

\section{Post-test assessment}

In the final phase, postintervention, all prescriptions written during the 1 month (June to July 2011) from

Table 2 Prescriptions with high-risk abbreviations across three sources categorised according to whether they were preintervention or postintervention

\begin{tabular}{|c|c|c|c|c|c|c|}
\hline \multirow[b]{2}{*}{ Prescription source } & \multicolumn{2}{|c|}{ Preintervention } & \multicolumn{2}{|c|}{ Postintervention } & \multirow[b]{2}{*}{$\begin{array}{l}\text { IRD† } \\
(\%)\end{array}$} & \multirow[b]{2}{*}{$\begin{array}{l}\chi^{2} \\
(\mathrm{df}=1)\end{array}$} \\
\hline & $\begin{array}{l}\text { Number of } \\
\text { patients }\end{array}$ & $\begin{array}{l}\text { Incidence* } \\
(\%)\end{array}$ & $\begin{array}{l}\text { Number of } \\
\text { patients }\end{array}$ & $\begin{array}{l}\text { Incidence* } \\
(\%)\end{array}$ & & \\
\hline $\begin{array}{l}\text { Hospital emergency wards (M/F } \\
\text { emergency departments) }\end{array}$ & 42 & $40.9(90 / 220)$ & 30 & $10.7(15 / 140)$ & 73.8 & $37.756 \ddagger$ \\
\hline Pharmacy department & 220 & $72.7(160 / 220)$ & 178 & $39.3(70 / 178)$ & 45.9 & $45.001 \ddagger$ \\
\hline Inpatient settings & 220 & $47.3(104 / 220)$ & 180 & $23.3(42 / 180)$ & 50.7 & $24.479 \ddagger$ \\
\hline Total & 482 & $53.6(354 / 660)$ & 388 & $25.5(127 / 498)$ & 52.4 & $92.517 \ddagger$ \\
\hline
\end{tabular}

*Incidence of high-risk abbreviation use calculated by using the equation:

$$
\text { Incidence }=\frac{\text { Number of prescriptions with at least one high }- \text { risk abbreviation }}{\text { Total number of prescriptions found in each source }} \times 100
$$

†Incidence rate decrease (IRD) can be calculated by

$$
\mathrm{IRD}=\frac{\mid \text { Post }- \text { intervention incidence }- \text { Pre }- \text { intervention incidence } \mid}{\text { Pre }- \text { intervention incidence }} \times 100
$$

$\ddagger \mathrm{p}=0.001$ (statistically significant at $\alpha=0.05$ ). 
the same three sources were re-evaluated using the same data collection form to assess the use of HRAs.

\section{Data analysis}

All the data collected were entered into Microsoft Excel 2010 (Microsoft Corporation, Redmond, Washington, USA) and PASW Statistics V.18 (SPSS-IBM Co, Chicago, Illinois, USA). Descriptive statistics were used to calculate the incidence of HRAs. A $\chi^{2}$ test for proportions was employed to analyse the difference in the incidence of HRAs with a significance level $(\alpha)$ of 0.05 using a two-tailed test.

\section{RESULTS}

A total of 660 prescriptions for 482 patients from three sources (emergency wards, the pharmacy department and inpatient ICU and CCU settings) were collected before the educational interventions, and 498 prescriptions (from 388 patient records) after the interventions. Details of all prescriptions with at least one HRA and the incidence of each HRA are set out in table 2. The highest incidence of HRA was found among discharge prescriptions and dispensing records kept in the pharmacy department $(72.7 \%)$, followed by prescriptions from inpatient settings $(47.3 \%)$ and prescription charts from hospital emergency wards $(40.9 \%)$. With respect to specific high-risk abbreviations, 14 of the 32 selected abbreviations were identified, as summarised in table 3 .
The five most common abbreviations recorded prior to the interventions were 'IJ for injection' (28.6\%), 'SC for subcutaneous' (17.4\%), drug name and dose running together $(9.7 \%)$, 'OD for once daily' $(5.8 \%)$ and 'D/C for discharge' $(4.3 \%)$. Although these abbreviations were noted across all three prescription sources, the abbreviation 'SC' occurred most frequently in hospital emergency services (15.4\%) and inpatient settings $(25.9 \%)$, while ' $\mathrm{IJ}$ ' was found principally in the pharmacy department $(52.7 \%)$.

After the intervention, the relative distribution of HRAs remained similar (ie, the pharmacy department remained the highest, etc), but there was a statistically significant reduction in the incidence of HRAs across all three sources: the pharmacy department $(72.7 \%$ vs $39.3 \%)$, inpatient settings ( $47.3 \%$ vs $23.3 \%)$ and emergency wards $(40.9 \%$ vs $10.7 \%$ ) (all $\mathrm{p}=0.001)$. The overall incidence of HRAs also decreased significantly by $52 \%$ after the interventions $(53.6 \%$ vs $25.5 \%$; $\mathrm{p}=0.001)$.

\section{DISCUSSION}

This is perhaps the first study of its kind in the Gulf region, particularly in Saudi Arabia, which evaluated the effectiveness of a pharmacist-led educational intervention to reduce the incidence of HRAs in acute care settings. Another study conducted in a large university hospital in Riyadh, Saudi Arabia reported a 65\%

Table 3 Frequencies of high-risk abbreviations recorded in prescriptions across three sources

\begin{tabular}{|c|c|c|c|c|c|c|c|c|}
\hline \multirow{2}{*}{ High-risk abbreviation } & \multicolumn{8}{|c|}{ Frequency of high-risk abbreviations* (\%) } \\
\hline & \multicolumn{2}{|c|}{$\begin{array}{l}\text { Hospital emergency } \\
\text { wards }\end{array}$} & \multicolumn{2}{|c|}{$\begin{array}{l}\text { Pharmacy } \\
\text { department }\end{array}$} & \multicolumn{2}{|c|}{ In-patient settings } & \multicolumn{2}{|l|}{ Total } \\
\hline 1. $\mu \mathrm{g}$ & 3.6 & 1.4 & 0 & 0 & 0 & 0 & 1.2 & 0.4 \\
\hline 2. $\mathrm{D} / \mathrm{C}$ & 5.4 & 0 & 7.7 & 1.6 & 0 & 0 & 4.3 & 0.5 \\
\hline 5. o.d. or OD & 7.7 & 0 & 7.7 & 1.1 & 2.2 & 0.5 & 5.8 & 0.5 \\
\hline 6. SC & 15.4 & 10.7 & 10.9 & 11.2 & 25.9 & 5.5 & 17.4 & 9.1 \\
\hline 7. $\mathrm{U}$ or $\mathrm{u}$ & 3.6 & 1.4 & 1.8 & 0 & 2.7 & 3.8 & 2.7 & 1.7 \\
\hline $\begin{array}{l}\text { 8. No leading zero } \\
\text { before a decimal point }\end{array}$ & 0.9 & 0 & 2.2 & 1.6 & 0 & 0 & 1.0 & 0.5 \\
\hline 11. ASA & 1.8 & 0 & 0 & 0 & 0.9 & 0 & 0.9 & 0 \\
\hline 12. / (slash) & 4.5 & 3.5 & 6.8 & 3.3 & 0 & 0 & 3.7 & 2.2 \\
\hline 13. \& (ampersand) & 3.6 & 0 & 2.2 & 0 & 0 & 0 & 1.9 & 0 \\
\hline 14.+ (plus sign) & 1.8 & 0 & 0 & 0 & 0 & 0 & 0.6 & 0 \\
\hline
\end{tabular}


decrease in use of unsafe abbreviations following the implementation of an educational intervention. ${ }^{23}$ The ISMP recommends that reduction of HRAs is one of the most effective strategies to improve standards of medication safety. ${ }^{13}$ This is especially because HRAs are closely linked to medical errors and life-threatening consequences but can be easily avoided when prescribing. ${ }^{8}$ In routine practice, the pharmacist occupies a key position where errors can be identified before medication is dispensed to patients or dispatched to a ward. It is vital, however, to educate the healthcare team to adopt a safety culture that aims to avoid or minimise the use of HRAs. In this study, it was seen that the overall incidence of HRAs was $53.6 \%$, which is higher than that reported by other studies. ${ }^{20}$

The educational interventions led by the pharmacist have been shown to have a positive effect on the behaviour of physicians with respect to the use of HRAs and significantly reduced the overall incidence, which is in line with the findings of other studies. ${ }^{20} 2324$ Taylor et $a t^{20}$ reported a $41 \%$ decrease in the incidence rate of HRAs following a pharmacist-led intervention $(31.8 \%$ vs $18.7 \%$ ). Moreover, Abushaiqa et al ${ }^{12}$ reported six abbreviations and dosage designations deemed unsafe, including ' $U$ for units', ' $\mu \mathrm{g}$ for microgram', 'TIW for three times a week', 'the degree $\left(^{\circ}\right)$ for hour', trailing zeros after a decimal point and the lack of a leading zero before a decimal. Of these, three items were also identified in our study as well: ' $U$ for units', ' $\mu \mathrm{g}$ for microgram' and the lack of a leading zero before a decimal. A possible explanation might be that these abbreviations are widely accepted; many prescribers have used them for decades and are reluctant to change. ${ }^{24}$ Although only 14 of 32 surveyed items were actually identified as occurring in this study, this does not imply that the remaining abbreviations are unimportant, as they might nonetheless be occasionally used by healthcare professionals.

Since the highest incidence of HRAs was noted in the discharge prescriptions and dispensing records kept in the Pharmacy department, pharmacists, as the last point of contact, are the key professionals for the prevention of medication errors. Meyer suggested that ongoing educational programmes, follow-up reminders and feedback to prescribers can greatly improve prescribers' prescription-writing habits. ${ }^{25}$ Accordingly, pharmacists should participate in an educational programme to help improve their prescription-writing skills with the use of acceptable abbreviations and feedback any medication errors on a regular basis.

\section{CLINICAL IMPLICATIONS}

There are a number of clinical implications for this study. First, the incidence of using HRAs in an acute care setting is alarmingly high, which may lead to medication errors, necessitating an action plan to discourage the use of HRAs. Second, a pharmacist-led educational intervention can potentially reduce the use of HRAs in clinical practice. Third, the use of handwritten prescriptions should be discouraged as they are sometimes illegible and prone to misinterpretation. Finally, healthcare professionals in Saudi Arabia are predominantly expatriates with a diverse educational, cultural and linguistic background, so it is important to develop safe prescribing guidelines at the local and national levels to ensure patient safety. In the USA, many organisations $^{24} 26-28$ dealing with patient safety have tried to discourage the use of error-prone abbreviations and dose expressions in healthcare settings over two decades, but the prescribing practice is only decreasing slowly. Similarly, in the UK, prescribers are encouraged to use English in place of Latin abbreviations. ${ }^{29}$ Interestingly, 'o. d. or OD for every day' and 'o.n. or ON for every night' are considered unsafe but are nonetheless commonly used in routine clinical practice. Educational interventions on a periodic basis can be one of the ways to modify prescriber behaviour and limit the use of HRAs.

\section{LIMITATION}

The findings of this study should be considered in the context of the study design limitations. There are two main limitations. First, randomised controlled trials (RCTs) are considered as the gold standard to evaluate the effectiveness of an intervention. ${ }^{19}$ However, quasi-experimental designs are ideal when conducting RCTs is either logistically or ethically not possible. ${ }^{18}$ We could not conduct an RCT due to the unavailability of a suitable control group, as this emergency centre is specifically designated for pilgrims only and there was no other such facility in the region. Owing to the lack of randomisation and control groups, several threats to the internal validity of before-and-after quasi-experimental studies have been reported in the literature including maturation, the Hawthorne effect, regression to the mean, dropout and testing. ${ }^{19}$ Second, the number of prescriptions reviewed during the post-intervention phase was about $25 \%$ less than that during the preintervention phase. As mentioned above, the study site is specifically designated for pilgrims and there are seasonal variations in the number of pilgrims. The decrease in patient numbers may have contributed to the decrease in the incidence of HRAs observed in the postintervention phase. However, the incidence of using HRAs was reduced by $52 \%$, which is significantly more than the decrease in the number of prescriptions seen in the post-intervention phase, suggesting a positive intervention effect.

\section{CONCLUSION}

Educational interventions led by pharmacists can be effective in reducing the use of HRAs by physicians and other healthcare providers, leading to a decrease in medication errors. In this study setting, the use of HRAs was noted to be high, which can compromise patient safety; therefore, it is essential for the regional and 
national Saudi health authorities to devise and implement policies and protocols to discourage the use of HRAs. Future research should explore the effectiveness of pharmacist-led interventions in reducing the use of HRAs in emergency and other settings using welldesigned randomised controlled trials.

\section{Author affiliations}

${ }^{1}$ Department of Clinical Pharmacy, College of Pharmacy, Umm Al-Qura University, Makkah, Kingdom of Saudi Arabia

${ }^{2}$ Department of Pharmacy Practice, School of Pharmacy, International Medical University, Kuala Lumpur, Malaysia

${ }^{3}$ Ajyad Emergency Hospital, Ministry of Health, Makkah, Kingdom of Saudi Arabia

${ }^{4}$ Pharmaceutical research center, Deanship of Scientific research, Umm Al Qura University, Mecca, Kingdom of Saudi Arabia

${ }^{5}$ Prince Sultan Military Medical City, Riyadh, Kingdom of Saudi Arabia

${ }^{6}$ King Faisal Specialist Hospital, Riyadh, Kingdom of Saudi Arabia

${ }^{7}$ Department of Preventive Medicines, University of Tennessee Health Science Center, University of Tennessee, Memphis, United States

${ }^{8}$ School of Pharmacy, Monash University Malaysia, Selangor, Malaysia

Acknowledgements The authors would like to thank the Pharmaceutical Research Centre, Deanship of Scientific Research, Umm Al-Qura University for funding this project. Further, the authors would like to thank Ajyad Emergency Hospital, and the Ministry of Health for their approval of this study. The authors feel grateful to Ahmad J Mahroos, Safa S. Al Murzooky and Sara M.S. Khayat for their help during the intervention phase. In addition, the authors acknowledge the assistance of all healthcare professionals for the data collection and for their valuable comments. The authors also express our gratitude to Richard from 'Amsterdam English lessons' for reviewing the final draft for grammatical errors and interpretation.

Contributors AH, WWW and TMK conceived the concept. A-RRB, MEE, AAM, AZG, BFA-I, RAA and RAE assisted in the data collection and interpretation. $\mathrm{AH}, \mathrm{WWW}, \mathrm{MAH}$ and TMK analysed the results. MAH, AH, WWW and MEE compiled the initial draft. TMK, MAH and AH finalised the draft. All authors equally contributed to the study and finalisation of the manuscript.

Funding The study was partially funded by the Pharmaceutical Research Centre, Deanship of Scientific Research, Umm Al-Qura University with respect to publication cost.

\section{Competing interests None declared.}

Ethics approval Research and Ethics Committee, Umul Qura University, Ajyad Emergency Hospital (Makkah) and the Ministry of Health regional office Makkah, Saudi Arabia.

Provenance and peer review Not commissioned; externally peer reviewed.

Data sharing statement No additional data are available.

Open Access This is an Open Access article distributed in accordance with the Creative Commons Attribution Non Commercial (CC BY-NC 4.0) license, which permits others to distribute, remix, adapt, build upon this work noncommercially, and license their derivative works on different terms, provided the original work is properly cited and the use is non-commercial. See: http:// creativecommons.org/licenses/by-nc/4.0/

\section{REFERENCES}

1. Institute of Medicine (IOM). To err is human: building a safer health system. Washington DC: National Academy Press, 2000.

2. Beardsley SR, Kimberlin LC, Tindall NW. Communication skills in pharmacy practice. 5th edn. Philadelphia, PA: Lippincott William \& Wilkins, 2008.
3. Institute of Medicine (IOM). Quality chasm series: preventing medication errors. Washington DC: National Academy Press, 2007.

4. Leape LL, Bates DW, Cullen DJ, et al. System analysis of adverse drug events. JAMA 1995;274:35-43.

5. Bates DW, Cullen DJ, Laird N, et al. Incidence of adverse drug events and potential adverse drug events. Implications for prevention. ADE Prevention Study Group. JAMA 1995;274:29-34.

6. Lesar TS, Briceland L, Stein DS. Factors related to errors in medication prescribing. JAMA 1997;277:312-17.

7. Dunn EB, Wolfe JJ. Let go of Latin! Vet Hum Toxicol 2001;43:235-6.

8. Brunetti L, Santell JP, Hicks RW. The impact of abbreviations on patient safety. Jt Comm J Qual Patient Saf 2007;33:576-83.

9. Conroy S, North C, Fox T, et al. Educational interventions to reduce prescribing errors. Arch Dis Child 2008;93:313-15.

10. Sandilands EA, Reid K, Shaw L, et al. Impact of a focused teaching programme on practical prescribing skills among final year medical students. Br J Clin Pharmacol 2011;71:29-33.

11. Ross S, Loke YK. Do educational interventions improve prescribing by medical students and junior doctors? A systematic review. $\mathrm{Br} \mathrm{J}$ Clin Pharmacol 2009;67:662-70.

12. Abushaiqa ME, Zaran FK, Bach DS, et al. Educational interventions to reduce use of unsafe abbreviations. Am J Health Syst Pharm 2007:64:1170-3.

13. American Institute for Safe Medication Prescribing (ISMP). ISMP list of error-prone abbreviations, symbols, and dose designations: ISMP medication safety alert! Horsham, PA: ISMP, 2004. http://www.ismp. org (accessed 15 Jan 2016).

14. U.S. Food and Drug Administration. FDA news release: FDA and ISMP launch campaign to reduce medication mistakes caused by unclear medical abbreviations. Silver Spring, MD: FDA, 2006. http:// www.fda.gov/NewsEvents/Newsroom/PressAnnouncements/2006/ ucm108671.html (accessed 15 Jan 2016).

15. NSW Therapeutic Advisory Group and Clinical Excellence Commission. Indicators for quality use of medicines in Australian hospitals. Darlinghurst, NSW: NSWTAB, 2007.

16. Al-Dhawailie AA. Inpatient prescribing errors and pharmacist intervention at a teaching hospital in Saudi Arabia. Saudi Pharm J 2011;19:193-6.

17. Al-Jeraisy MI, Alanazi MQ, Abolfotouh MA. Medication prescribing errors in a pediatric inpatient tertiary care setting in Saudi Arabia. BMC Res Notes 2011;4:294.

18. Harris AD, Bradham DD, Baumgarten $M$, et al. The use and interpretation of Quasi-experimental studies in infectious diseases. Clin Infect Dis 2004;38:1586-91.

19. Sibbald $B$, Roland $M$. Understanding controlled trials: why are randomised controlled trials important? BMJ 1998;316:201.

20. Taylor SE, Chu MTY, Haack LE, et al. An intervention to reduce the use of error-prone prescribing abbreviations in the Emergency Department. J Pharm Pract Res 2007;37:214-16.

21. Wick JY. How to eliminate "do not use" abbreviations. Consult Pharm 2007:22:870-3.

22. Gaunt MJ, Cohen MR. Error-prone abbreviations and dose expressions. In: Cohen MR, eds. Medication errors. 2nd edn. Washington DC: American Pharmacists Association, 2007:153-71.

23. Alshaikh M, Mayet A, Adam M, et al. Intervention to reduce the use of unsafe abbreviations in a teaching hospital. Saudi Pharm $J$ 2013;21:277-80.

24. American Society of Health-System Pharmacist (ASHP). ASHP guidelines on preventing medication errors in hospital. Am J Hosp Pharm 1993;50:305-14.

25. Meyer TA. Improving the quality of the order-writing process for inpatient orders and outpatient prescriptions. Am J Health Syst Pharm 2000;57(Suppl 4):S18-22.

26. National Coordinating Council for Medication Error Reporting and Prevention (NCC MERP). Council recommendations: recommendations to enhance accuracy prescription writing. Rockville, MD: NCC MERP, 2005 (cited 12 May 2011). http://www. nccmerp.org/councilRec.html

27. National Quality Forum (NQF). Safe practices for better health care: a consensus report. Washington DC: NQF, 2003.

28. Joint Commission on Accreditation of Health Care Organizations (JCAHO). Critical access hospital: 2012 national patient safety goals. Washington DC: JCAHO, 2011 (cited 11 May 2011). http:// www.jointcommission.org/standards_information/npsgs.aspx

29. British Medical Association and Royal Pharmaceutical Society British National Formulary: BNF63. London: BMJ Group and Pharmaceutical Press, 2012. 